\title{
Coating of urea granules by in situ polymerization in fluidized bed reactors
}

\author{
Bruno Souza Fernandes ${ }^{1}$, José Carlos Pintoํㄹ ${ }^{2}$ Elaine Christine de Magalhães Cabral-Albuquerque ${ }^{3}$ and \\ Rosana Lopes Lima Fialho ${ }^{3 *}$
}

\author{
${ }^{1}$ Centro de Ciência e Tecnologia em Energia e Sustentabilidade, Universidade Federal do \\ Recôncavo da Bahia - UFRB, Feira de Santana, BA, Brasil \\ ${ }^{2}$ Laboratório de Engenharia de Polimerização, Programa de Engenharia Química, Instituto Alberto \\ Luiz Coimbra de Pós-graduação e Pesquisa de Engenharia - COPPE, Universidade Federal do \\ Rio de Janeiro - UFRJ, Rio de Janeiro, RJ, Brasil \\ ${ }^{3}$ Laboratório de Polímeros e Bioprocessos, Programa de Pós-graduação em Engenharia Industrial, \\ Universidade Federal da Bahia - UFBA, Salvador, BA, Brasil \\ *rosanafialho@ufba.br
}

\begin{abstract}
The main objective of the present work is to produce and characterize urea granules coated with polymers prepared with aqueous solutions of acrylic acid and glycerol. Both coating and drying of urea granules were performed in a fluidized bed reactor. Fourier transform infrared spectroscopy analyses indicated the presence of poly(acrylic acid) and acrylic acid / glycerol copolymers on the granule coating and the formation of chemical bonds between urea and the polymer coating. Scanning electron microscopy images showed that the original and coated urea granules presented different characteristics, reinforcing the idea that coating occurs in the fluidized bed. Finally, rates of urea release showed that the coated granules presented slightly slower rates of urea dissolution in water due to the presence of the coating layer. Therefore, it is shown that it is possible to produce coated urea granules through in-situ polymerization onto the granule surface using a fluidized bed.
\end{abstract}

Keywords: acrylic acid, coating, fluidized bed, glycerol, urea.

How to cite: Fernandes, B. S., Pinto, J. C., Cabral-Albuquerque, E. C. M., \& Fialho, R. L. L. (2019). Coating of urea granules by in situ polymerization in fluidized bed reactors. Polímeros: Ciência e Tecnologia, 29(1), e2019004. https:// doi.org/10.1590/0104-1428.06617

\section{Introduction}

Urea is the fertilizer used most often in agriculture; for this reason, the worldwide production and consumption of urea has steadily increased in recent years. Urea is characterized by its high nitrogen content ( $46 \mathrm{wt} \%$ ), low production cost and high water solubility. In addition, urea is noncorrosive and can be easily mixed with other compounds ${ }^{[1-3]}$. The main problem associated with the use of urea as a fertilizer is the high rate of loss to the environment through leaching and volatilization $^{[3-5]}$. Losses can reach $50 \mathrm{wt} \%$ of the applied urea fertilizer, depending on the climate, soil conditions and application technologies, causing environmental pollution and increasing the costs of crop production ${ }^{[6-10]}$.

A possible alternative to reduce nutrient losses is the development of slow-release fertilizers by coating urea granules with materials that feature lower water solubility ${ }^{[5,9,10]}$ or by using materials that allow for the slow release of urea ${ }^{[8,11-14]}$. Particularly, the production of slow-release urea products with help of polymer coatings constitutes a promising technological solution for many applications ${ }^{[7,9,15]}$.

The use of poly(acrylic acid), PAA, obtained through free-radical polymerization of acrylic acid in aqueous medium

presents a number of comparative advantages in various applications, including the low cost, biodegradability and good biocompatibility. PAA-based resins can also exhibit high capacity of water absorption and retention and can be possibly used for production of superabsorbent coatings and manufacture of slow-release fertilizers ${ }^{[16-22]}$. It is also important to observe that glycerol can act as a chain transfer agent, esterification and/or a crosslinking agent in some free-radical and functional polymerizations, and particularly in aqueous free-radical acrylic acid polymerizations, leading to formation of chain branches and modifying the molecular weight distributions of the final products ${ }^{[23,24]}$. For this reason, glycerol has been used frequently as a comonomer in aqueous free-radical acrylic acid polymerizations.

Based on the previous remarks, the main objective of the present study was to produce coated urea granules in a fluidized bed reactor, using polymer materials produced in-situ and ex-situ through aqueous free-radical polymerizations of acrylic acid and glycerol. The coated and uncoated urea granules were characterized by Fourier transform infrared spectroscopy (FTIR), scanning electron microscopy (SEM) 
and rates of urea release in distilled water. The obtained results indicated that polymer coating was performed successfully in all analyzed cases, confirming that in-situ polymerization of the monomer solution on the urea granules is possible in fluidized bed reactors. Particularly, FTIR analyses indicated the presence of poly(acrylic acid) and acrylic acid / glycerol copolymers on the granule coating and the formation of chemical bonds between urea and the polymer coating. SEM images showed that the original and coated urea granules presented different characteristics, reinforcing the idea that coating occurs in the fluidized bed. Finally, rates of urea release showed that the coated granules presented slightly slower rates of urea dissolution in water due to the presence of the coating layer.

\section{Materials and Methods}

\subsection{Materials}

Urea $\left(\mathrm{CO}\left(\mathrm{NH}_{2}\right)_{2}\right.$, with minimum purity of $99.5 \mathrm{wt} \%$, containing $46.4 \mathrm{wt} \%$ of nitrogen, with $\mathrm{M}_{\mathrm{w}}$ of $60.07 \mathrm{~g} \cdot \mathrm{mol}^{-1}$ ) was provided in the form of granules (average particle size of $1.84 \mathrm{~mm}$ ) by Petrobras (Camaçari, Bahia, Brazil). Acrylic acid $\left(\mathrm{C}_{3} \mathrm{H}_{4} \mathrm{O}_{2}\right.$, with minimum purity of $99.5 \mathrm{wt} \%$ and $\mathrm{M}_{\mathrm{w}}$ of $\left.72.02 \mathrm{~g} . \mathrm{mol}^{-1}\right)$, glycerol $\left(\mathrm{C}_{3} \mathrm{H}_{8} \mathrm{O}_{3}\right.$, with minimum purity of $99.5 \mathrm{wt} \%$ and $\mathrm{M}_{\mathrm{w}}$ of $\left.92.1 \mathrm{~g}^{\mathrm{g}} \mathrm{mol}^{-1}\right)$ and potassium persulfate $\left(\mathrm{K}_{2} \mathrm{~S}_{2} \mathrm{O}_{8}\right.$, with minimum purity of $99.0 \mathrm{wt} \%$ and $\mathrm{M}_{\mathrm{w}}$ of $270.32 \mathrm{~g} \cdot \mathrm{mol}^{-1}$ ) were acquired from Vetec (Duque de Caxias, Brazil). The enzyme urease and other reagents used to hydrolyze urea and determine the urea content of analyzed samples were provided by Doles (Goiânia, Brazil) as the enzymatic kit Urea 500. All reagents and solvents used for polymer characterization were purchased at analytical grades from Vetec (Duque de Caxias, Brazil). All chemicals were used as received.

\subsection{Coating of urea granules}

The coating of urea granules was conducted in two ways. First, a copolymer was produced prior to coating in the fluidized bed. In the second, copolymerization and coating occurred simultaneously in the fluidized bed.

Detailing the first way, the copolymerization reactions were performed in an Atlas Sodium reactor (Syrris, United Kingdom). Copolymerization reactions were conducted in distilled water by mixing $100 \mathrm{~g}$ of the aqueous initiator solution and $200 \mathrm{~g}$ of the aqueous monomer solution. The final reacting mixture contained $3.00 \mathrm{~g}$ of potassium persulfate, $39.80 \mathrm{~g}$ of urea, $23.86 \mathrm{~g}$ of acrylic acid and $3.00 \mathrm{~g}$ of glycerol. Reactions were performed in a 500 -mL glass flask, with mechanical stirring of $300 \mathrm{rpm}$, temperature of $80{ }^{\circ} \mathrm{C}$ and time of $2 \mathrm{~h}$, in accordance with previous experimental studies $^{[18,25-28]}$. As the final copolymer medium was biphasic (a lighter and less viscous liquid phase and a heavier viscous liquid phase, which contained the copolymer), continuous stirring of the copolymer feed was necessary to prevent heterogeneous and varying feed conditions.

Detailing the second way, the monomer solution used to perform the coating of urea granules through in-situ copolymerization inside the fluidized bed reactor contained $3.00 \mathrm{~g}$ of potassium persulfate, $63.66 \mathrm{~g}$ of acrylic acid, $3.00 \mathrm{~g}$ of glycerol and $230.34 \mathrm{~g}$ of distilled water.
Coating and drying of the urea granules were performed in a Midi Model Fluidized Bed Reactor (Glatt, Germany) with height of $900 \mathrm{~mm}$, width of $700 \mathrm{~mm}$ and length of $740 \mathrm{~mm}$. The coating process in the fluidized bed reactor was conducted with $300 \mathrm{~g}$ of urea granules and $100 \mathrm{~mL}$ of the respective coating solutions. In all cases, the fluidization pressure was kept constant and equal to 0.8 bar. The atomization pressure was equal to 0.5 bar and $1.0 \mathrm{bar}$, when the monomer and polymer solutions were used for coating, respectively. The feed flow rate of the coating solution was constant and equal to $5 \mathrm{~mL} / \mathrm{min}$. The temperature of the fluidizing air was equal to $80{ }^{\circ} \mathrm{C}$. The blow down rate was 1 every $4 \mathrm{~s}$. The height of the cylindrical partition, which was parallel with the largest mouth of the bed, was $6.5 \mathrm{~cm}$.

The coating process was conducted with intermittent interruption of the feed flow rate of the coating solution in order to prevent particle agglomeration, as described elsewhere ${ }^{[29-31]}$. Usually, feed flow rates were kept constant for periods of $20 \mathrm{~s}$ and stopped for periods of $1 \mathrm{~min}$ and $40 \mathrm{~s}$. Coating operations were performed as presented in Table 1.

\subsection{Fourier Transform Infrared Spectroscopy (FTIR)}

Coated and uncoated samples of urea granules were analyzed by FTIR using a Vertex 70 Spectrophotometer (Bruker, United States), equipped with Attenuated Total Reflectance (ATR) probe and operating in the range of $4000-600 \mathrm{~cm}^{-1}$. Spectral data were reported as averages of 50 readings obtained with resolution of $2 \mathrm{~cm}^{-1}$ at $16 \pm 1{ }^{\circ} \mathrm{C}$. The backgrounds were collected using uncoated urea granules in order to reduce the effect of the urea signal.

\subsection{Scanning Electron Microscopy (SEM)}

Coated and uncoated samples of urea granules were also evaluated by SEM. Granules were placed onto double-sided carbon tapes and affixed to gold-coated aluminum carriers. A Quanta 400 model SEM Microscope (FEI Company, United States), with maximum operation voltage of $30 \mathrm{kV}$ and nominal resolution of $1.2 \mathrm{~nm}$ in high vacuum and equipped with a SE (secondary electron) detector, was used. In all cases, the voltage was set at $20 \mathrm{kV}$ and the images were acquired with the SE detector.

\subsection{Urea release in water}

Analyses of urea release profiles were performed in distilled water in order to compare the relative performances of coated and uncoated urea granules. Coated and uncoated urea samples were weighed to provide $0.80 \mathrm{mg}$ of urea per $\mathrm{mL}$ of water. Tests were performed in $25 \mathrm{~mL}$ of distilled water at $30^{\circ} \mathrm{C}$. The aqueous solution containing the sample was kept under continuous magnetic stirring of $100 \mathrm{rpm}$. $10-\mu \mathrm{L}$ samples of the aqueous solutions were withdrawn for analyses at time intervals of 1, 5, 10, 20,30,60 and $90 \mathrm{~min}$.

Table 1. Coatings performed in the fluidized bed reactor.

\begin{tabular}{ccc}
\hline Coating & Solution & Pauses in solution feed \\
\hline 1 & Monomer & No \\
2 & Monomer & Yes \\
3 & Polymer & No \\
4 & Polymer & Yes \\
\hline
\end{tabular}


The total volume of the system was kept constant through addition of distilled water immediately after sampling.

The urea concentration was determined enzymatically with help of the Urea 500 kit. Ammonia concentrations (and therefore, concentrations of urea) were obtained at room temperature with help of a calibration model, using a UV-visible spectrophotometer (Lambda 35 model, Perkin Elmer, United States) operating in the wavelength range of 570 to $720 \mathrm{~nm}$. The wavelength considered for calculation and determination of the released urea content was equal to $600 \mathrm{~nm}$.

\section{Results and Discussions}

\subsection{Fourier Transform Infrared Spectroscopy (FTIR)}

Figure 1 shows the FTIR spectra of coated and uncoated urea granules. One can observe the characteristic urea peaks at $3430-3336 \mathrm{~cm}^{-1}$, which correspond to the symmetrical stretching of NH. The peak placed at $1675 \mathrm{~cm}^{-1}$ corresponds to the stretching of the double bond $\mathrm{C}=\mathrm{O}$, while the peak positioned at $1590 \mathrm{~cm}^{-1}$ is related to the stretching of bonds in $\mathrm{NH}$ or $\mathrm{NH}_{2}$. The peaks placed at $1460 \mathrm{~cm}^{-1}$ and $1003 \mathrm{~cm}^{-1}$ correspond to the shortening of the $\mathrm{CN}$ bond, while the peak

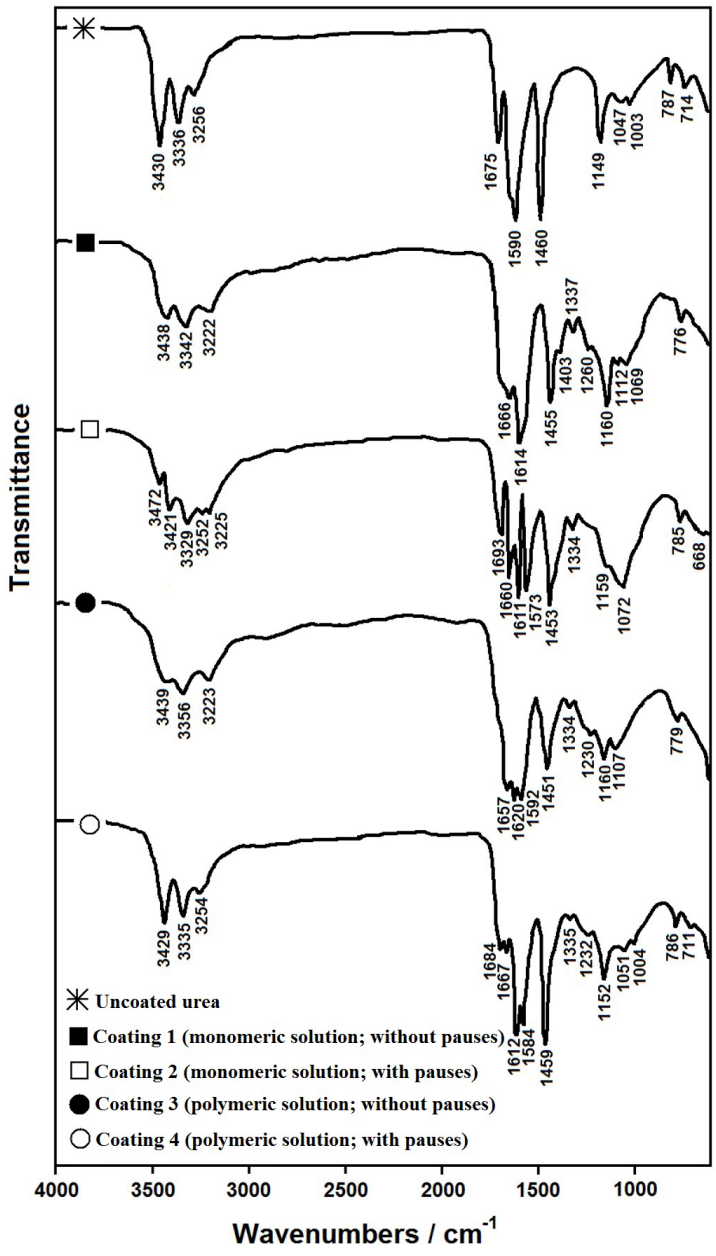

Figure 1. FTIR spectra of the uncoated and coated urea granules. positioned at $1149 \mathrm{~cm}^{-1}$ is due to the symmetrical stretching of $\mathrm{NH}$. The peak placed at $787 \mathrm{~cm}^{-1}$ corresponds to the out-of-phase bending of OCNN, while the peak placed at $714 \mathrm{~cm}^{-1}$ corresponds to the bending of the NH bond. These results were reported in previous studies ${ }^{[32-34]}$.

With regard to the coated urea granules, it is worth noting that all spectra showed the characteristic NH peaks of urea (near 3430-3336 cm-1 ), although with lower intensity. This indicates the existence of additional materials, changes of the chemical structure of the urea and new bonds of the $\mathrm{NH}$ group of urea with acrylic acid. The appearance of the peaks at $3472 \mathrm{~cm}^{-1}$ and $3225 \mathrm{~cm}^{-1}$ and the analysis of some peaks in the range of $1700-1100 \mathrm{~cm}^{-1}$ justify this statement.

Coating 1 presented a peak of high intensity at $1614 \mathrm{~cm}^{-1}$, revealing the presence of the bond $\mathrm{C}=\mathrm{C}$ of acrylic acid and the appearance of low-intensity peaks at $1403 \mathrm{~cm}^{-1}$, $1337 \mathrm{~cm}^{-1}, 1260 \mathrm{~cm}^{-1}$ and $1112 \mathrm{~cm}^{-1}$. These peaks indicate the presence of acrylic acid and formation of PAA and acrylic acid / glycerol copolymers, indicating the in-situ polymerization of the monomer solution and the physical interaction of polymer materials with the urea granules.

Coating 2 presented two new peaks in the characteristic $\mathrm{NH}$ spectral region of urea. In addition to the peaks placed at $3421 \mathrm{~cm}^{-1}, 3329 \mathrm{~cm}^{-1}$ and $3252 \mathrm{~cm}^{-1}$, peaks positioned at $3472 \mathrm{~cm}^{-1}$ and $3225 \mathrm{~cm}^{-1}$ showed that the NH group of urea interacted with the polymer coating. The peak placed at $1693 \mathrm{~cm}^{-1}$ showed the formation of the group CONHR between the urea granules and the carboxylic group of the monomer. The peak placed at $1159 \mathrm{~cm}^{-1}$ indicated the formation of the COC group, through reaction of acrylic acid and glycerol. Therefore, it seems clear that both in-situ polymerization and chemical interactions between the polymer coating and the urea granules took place in the fluidized bed.

The FTIR spectrum of Coating 3 was similar to the FTIR spectrum of Coating 1. As the coating operation was performed with the polymer solution in this case supports the idea that in-situ polymerizations did occur during preparation of Coatings 1 and 2 . The peak placed at $1160 \mathrm{~cm}^{-1}$, which was also present in the first two coatings, indicates the existence of $\mathrm{COC}$ groups due to reaction between acrylic acid and glycerol. Furthermore, the peak positioned at $1620 \mathrm{~cm}^{-1}$ indicates the formation of $\mathrm{NH}_{3}^{+}$ and $\mathrm{HCOO}^{-}$groups, formed through reaction of carboxylic groups of acrylic acid and amino groups of urea during the polymerization reaction or coating.

Coating 4 also showed the characteristic peaks that reveal the presence of the copolymer on the urea granules $\left(1612 \mathrm{~cm}^{-1}, 1335 \mathrm{~cm}^{-1}, 1232 \mathrm{~cm}^{-1}\right)$. In particular, the peak placed at $1684 \mathrm{~cm}^{-1}$ may indicate the formation of a CONHR group between the urea and the copolymer, due to reaction between the carboxylic groups of acrylic acid and amino groups of urea during the polymerization reaction or coating.

\subsection{Scanning Electron Microscopy (SEM)}

Figures 2, 3, 4, 5 and 6 show SEM images of uncoated and coated urea granules with various levels of magnification in order to provide better visualization and allow for proper comparison of the images. 
As one can observe in Figure 2, urea granules present spherical geometry, crystalline structure and irregular surfaces, with large pores. When the magnification reaches $5,000 \times$ and $10,000 \times$, the presence of canes can be observed in several directions on the surface of the urea granules.
Costa et al. ${ }^{[35]}$ described the surface of the urea as having a uniform and wrinkled appearance.

Samples prepared through Coating 1 featured fairly regular surfaces with small pores. First, this indicates the presence of the coating on the surfaces of the urea granules. a)

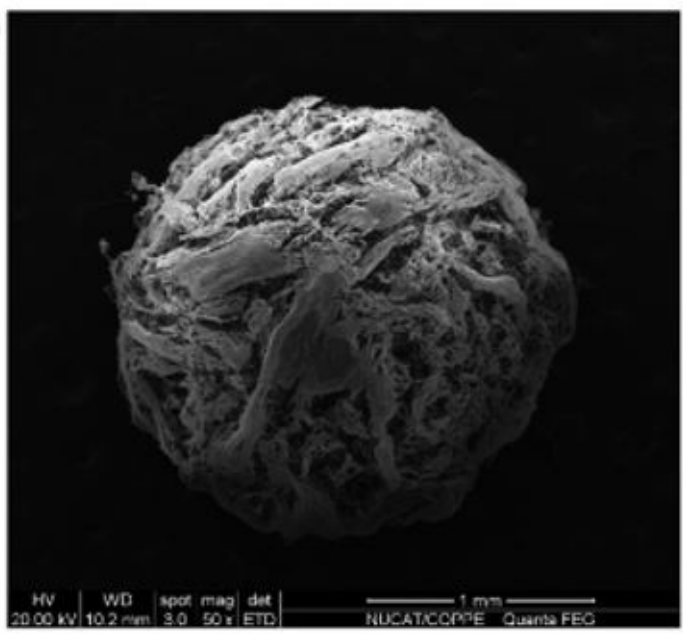

c)

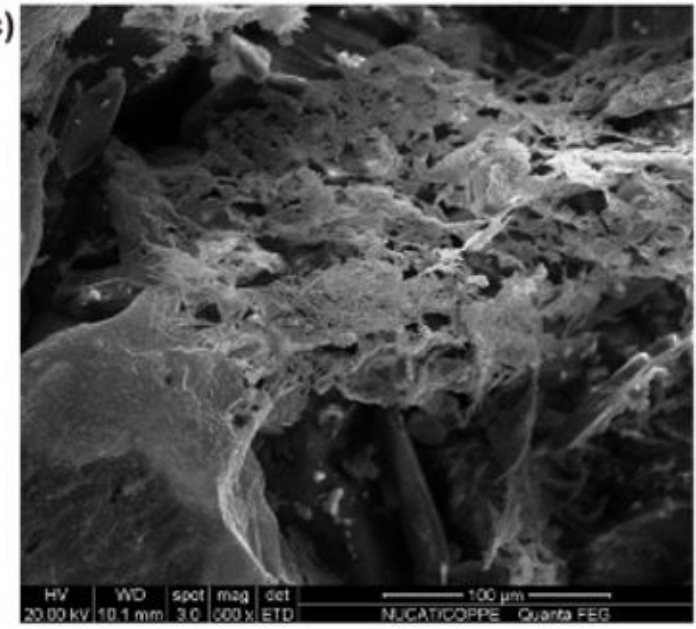

e)

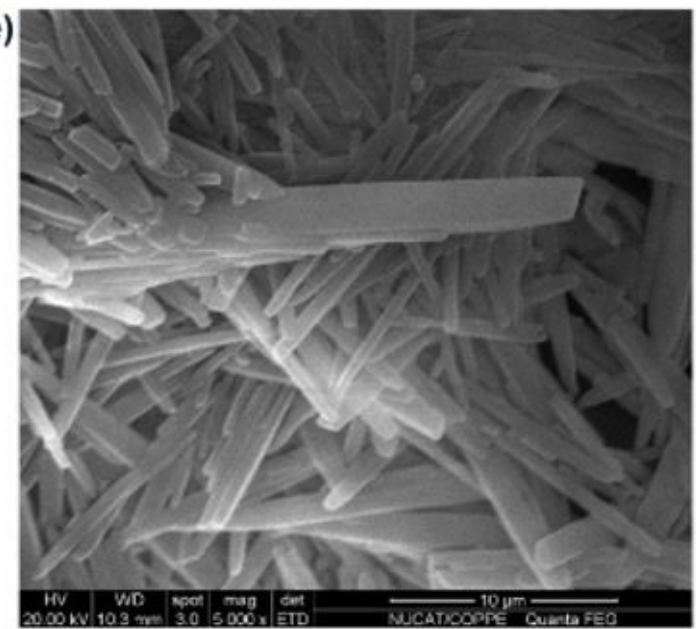

b)

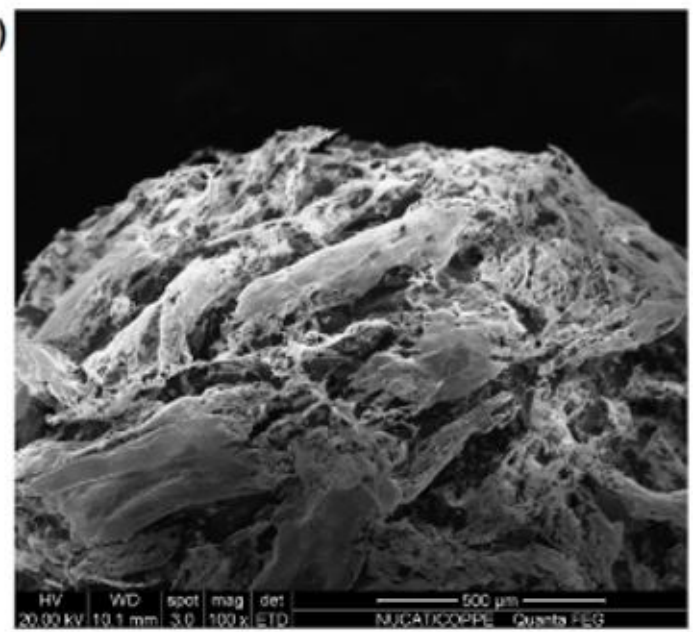

d)

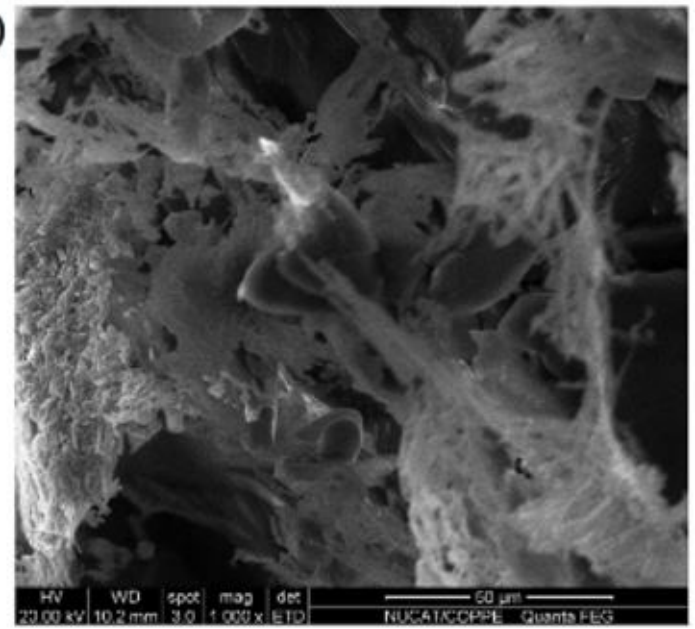

f)

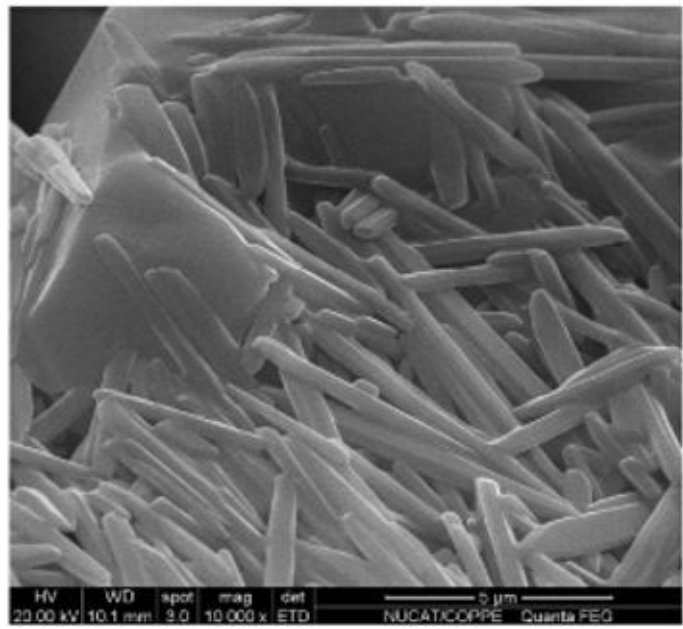

Figure 2. Images of uncoated urea obtained by SEM at magnifications of (a) 50×; (b) 100×; (c) 500×; (d) 1,000×; (e) 5,000×; and (f) 10,000× 
The characteristic canes of urea granules disappeared, indicating good level of particle finishing. Furthermore, the high regularity and low roughness of the surface possibly indicate that the monomers were converted to copolymers during coating.

a)

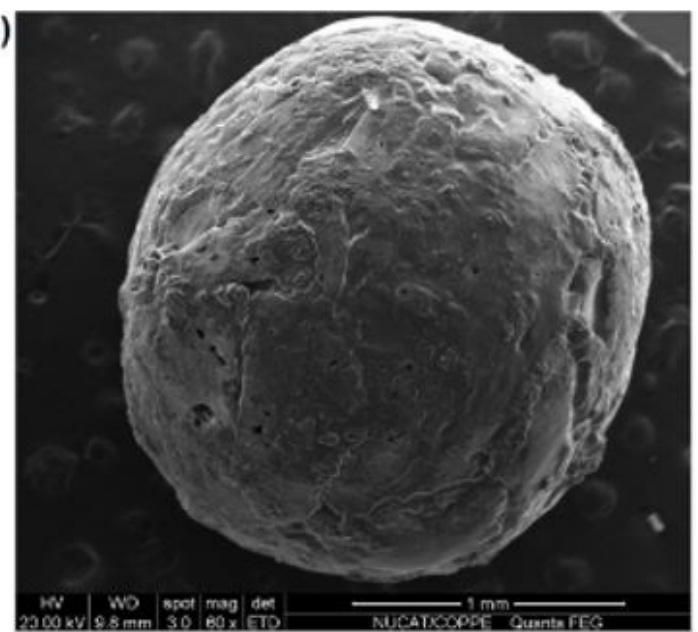

c)

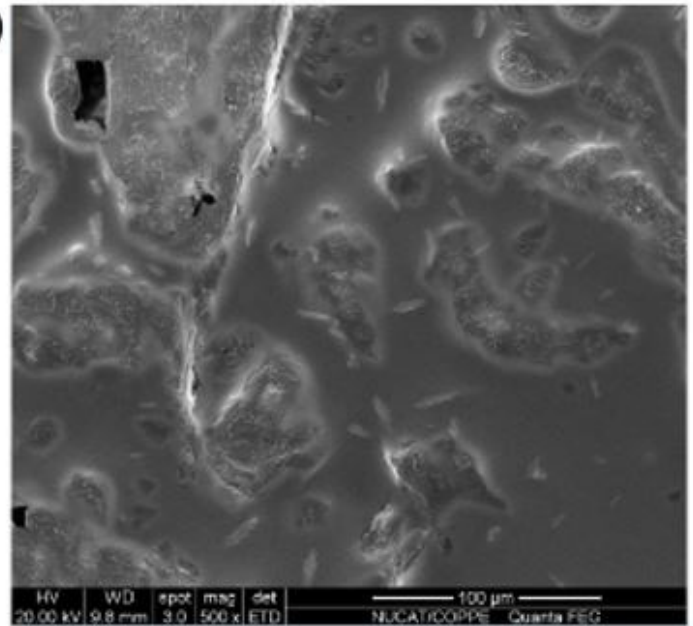

e)

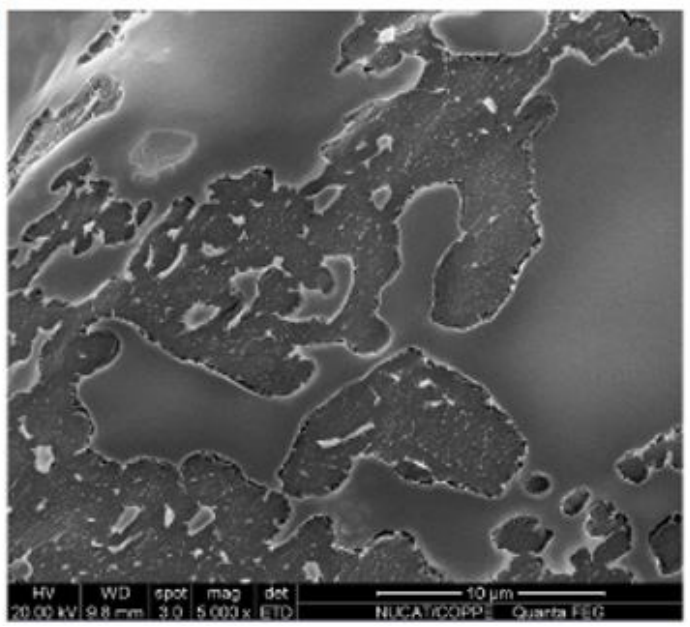

Samples prepared through Coating 3, which used the polymer solution, presented a rather uneven and rougher surface and also exhibited a darker region, where coating could not be applied or was applied to a lesser extent. These characteristics of the coating were probably due to b)

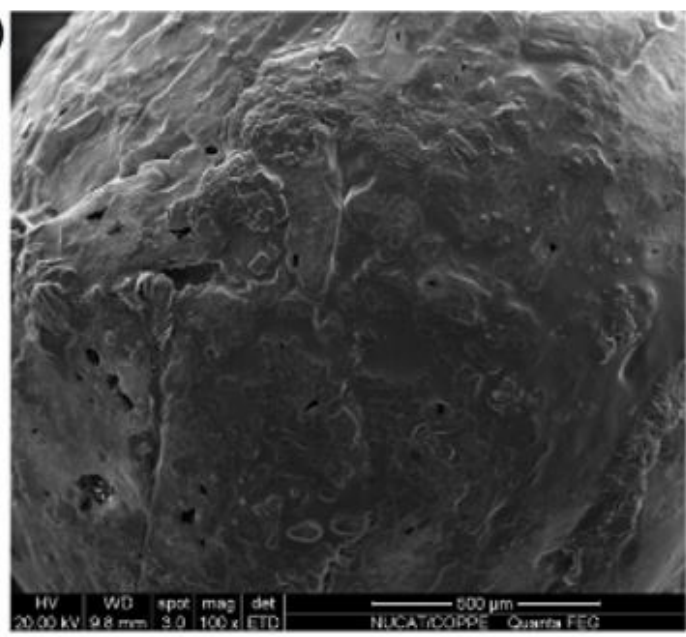

d)

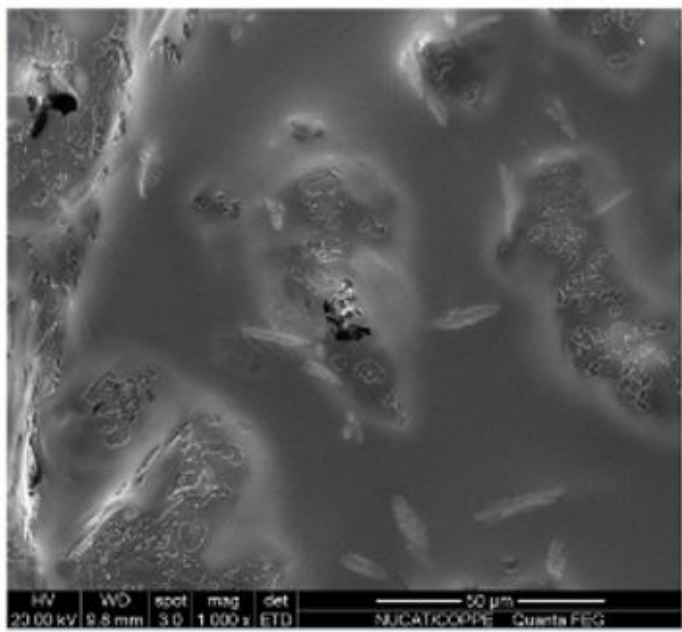

f)

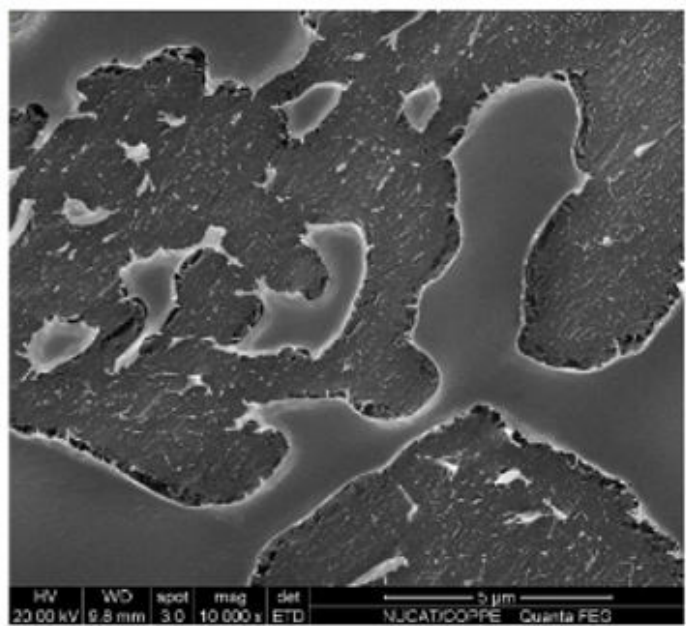

Figure 3. Images of coating 1 (monomeric solution; without pauses) obtained by SEM at magnifications of (a) 50×; (b) 100×; (c) 500×; (d) $1,000 \times$; (e) $5,000 \times$; and (f) $10,000 \times$. 
the higher viscosity of the copolymer solution, which can prevent the uniform distribution of polymer material on the granule surface, leading to formation of a less regular and rougher surface during drying. In addition, it can be seen that the geometry of the urea granules was less spherical, as there was larger concentration of coating in some parts of the urea granules than in others.

Samples prepared through Coating 4 were similar to samples prepared through Coating 3 , with uneven covering of the granule surfaces and formation of rough coating a)

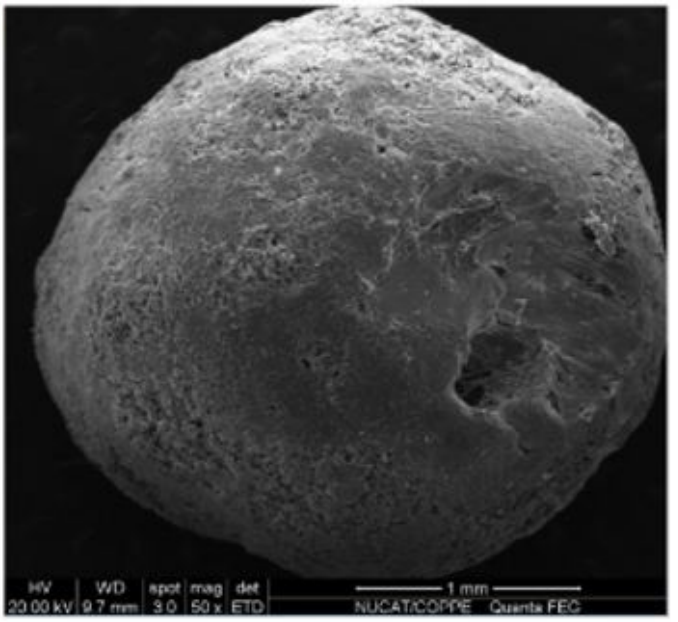

c)

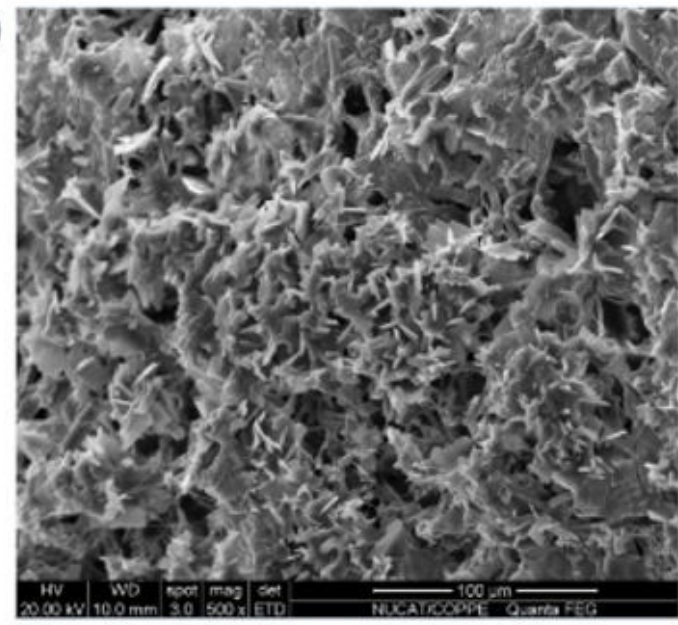

e)

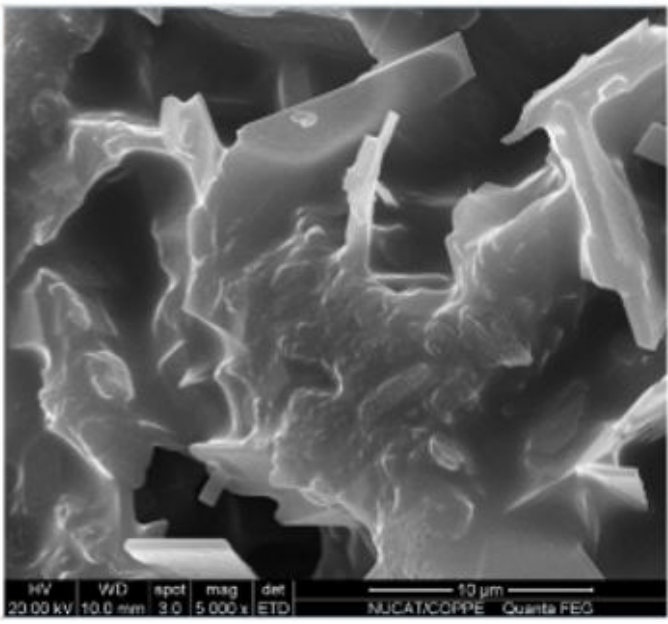

b)

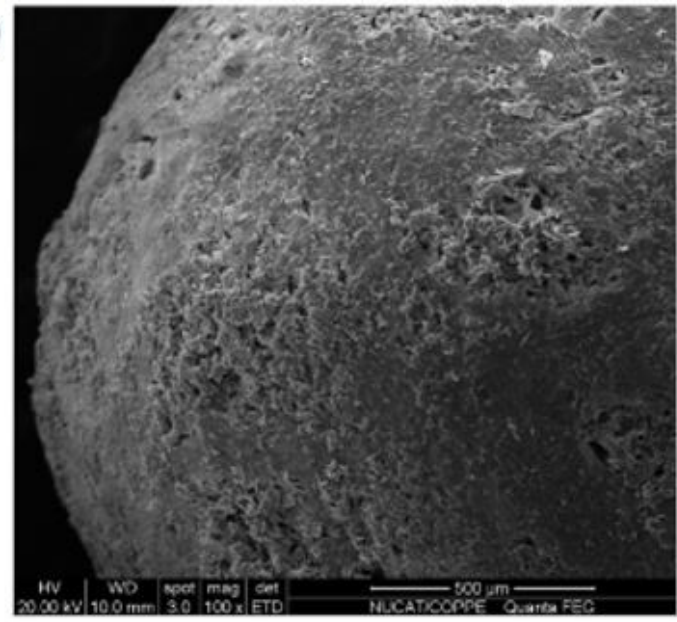

d)

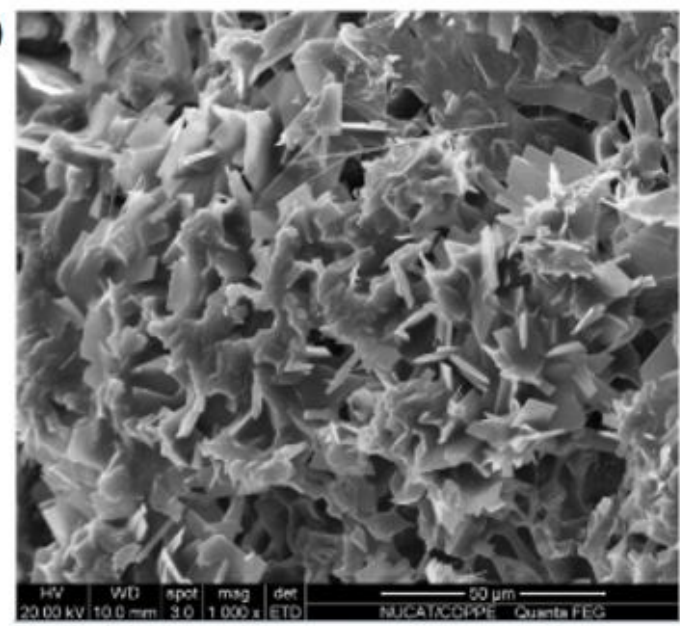

f)

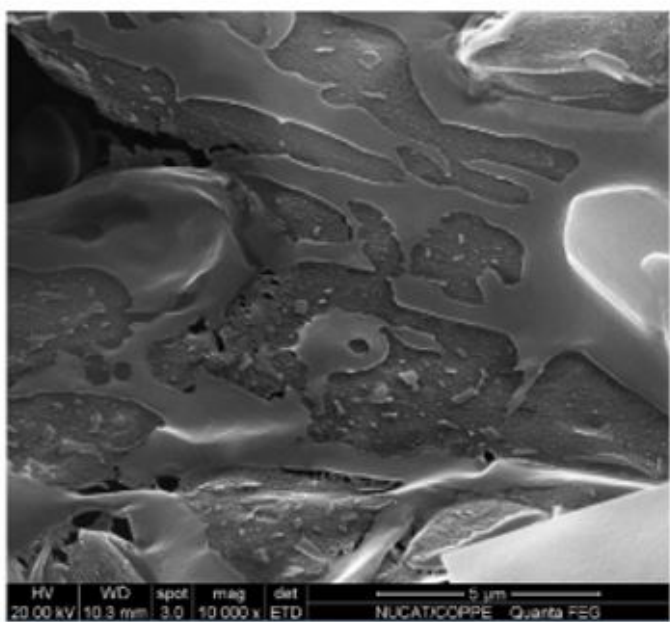

Figure 4. Images of coating 2 (monomeric solution; with pauses) obtained by SEM at magnifications of (a) $50 \times$; (b) $100 \times$; (c) $500 \times$; (d) $1,000 \times$; (e) $5,000 \times$; and (f) $10,000 \times$. 
layers. The dark regions of the surface presented lower degree of coating and granules lost the characteristic spherical geometry of urea particles, due to accumulation of coating on some parts of the urea granule. However, in this case, irregularity and roughness of the outer layer seemed to be smaller to some extent, indicating that the pauses in the flow rate during coating and the more regular drying operation allowed for better uniformity and distribution of the copolymer over the entire surface of the urea granules. a)

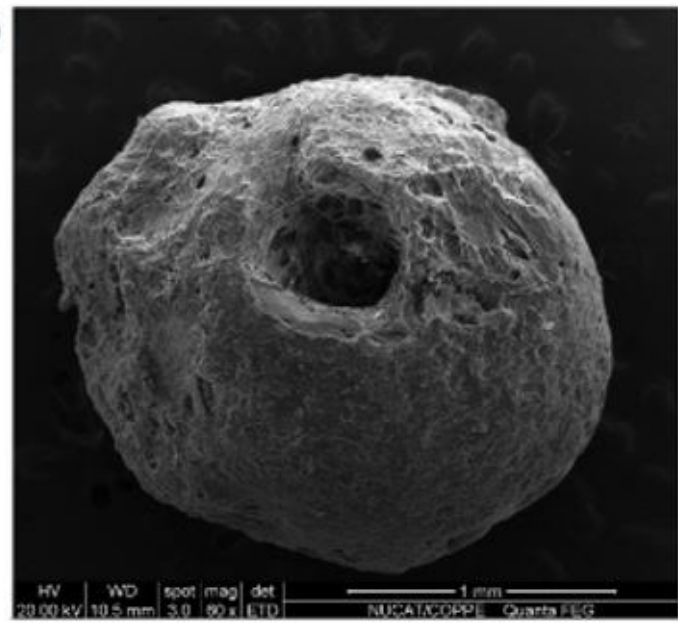

c)

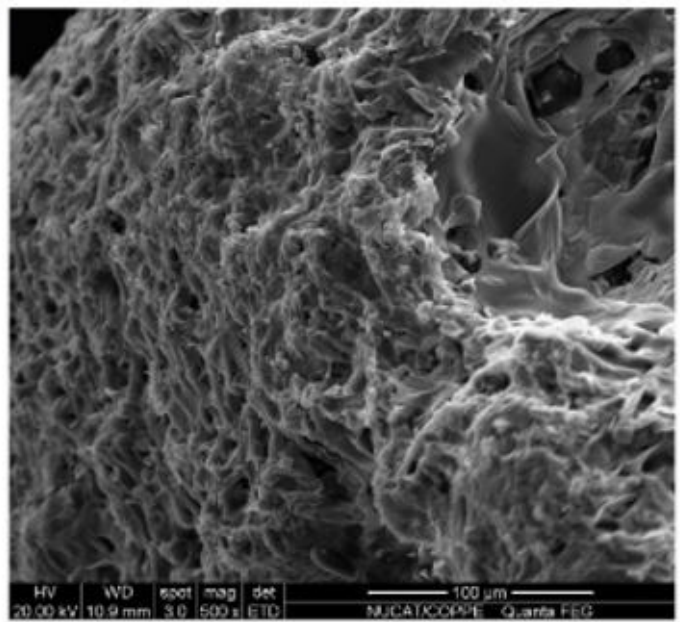

e)

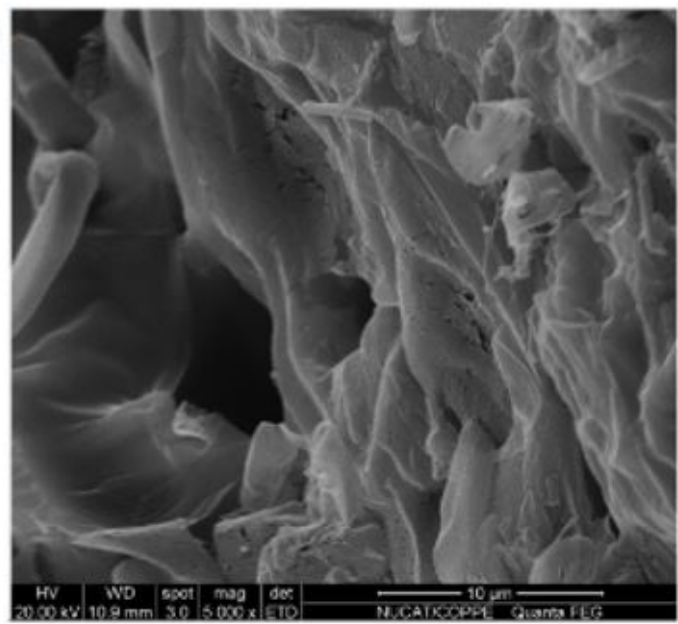

b)

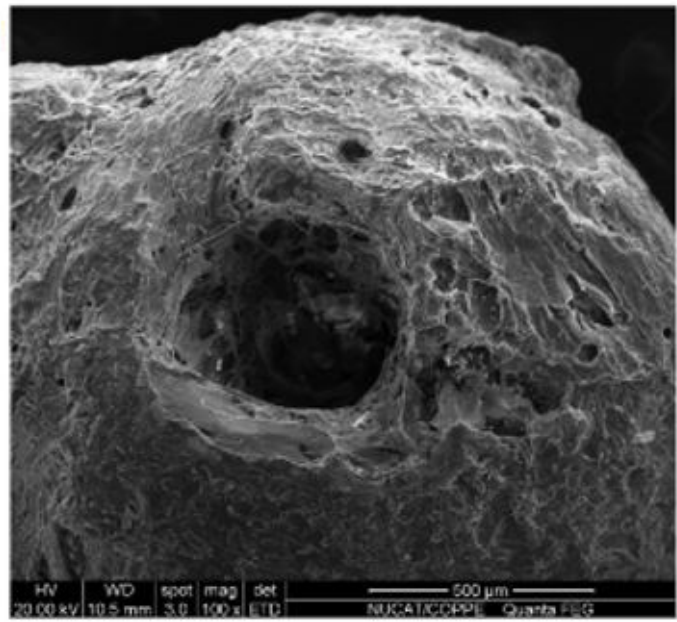

d)

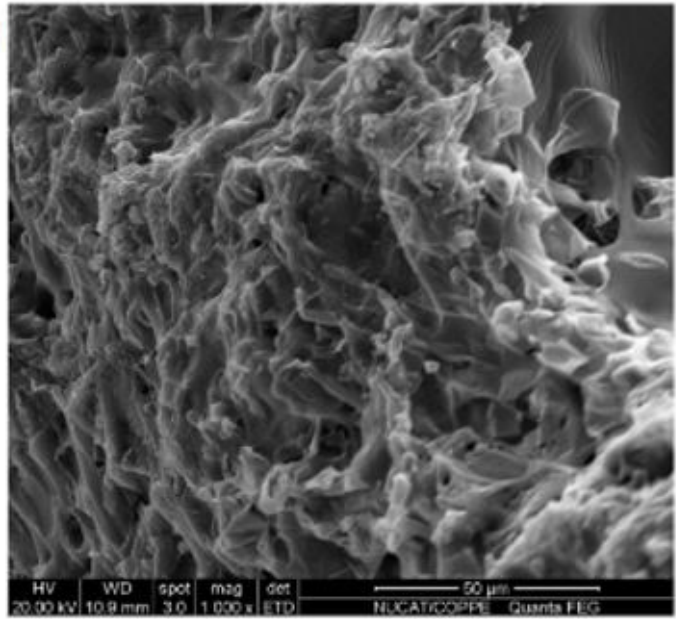

f)

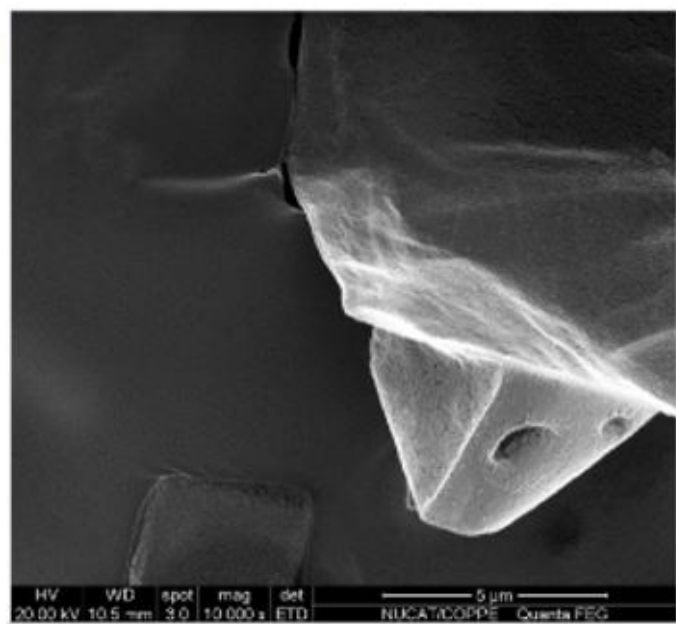

Figure 5. Images of coating 3 (polymeric solution; without pauses) obtained by SEM at magnifications of (a) 50×; (b) 100×; (c) 500×; (d) $1,000 \times$; (e) $5,000 \times$; and (f) $10,000 \times$. 
Samples prepared through Coating 2 exhibited intermediate characteristics between samples prepared through Coating 1 (using the monomer solution) and Coatings 3 and 4 (using the polymer solution). In this case, samples presented

a)

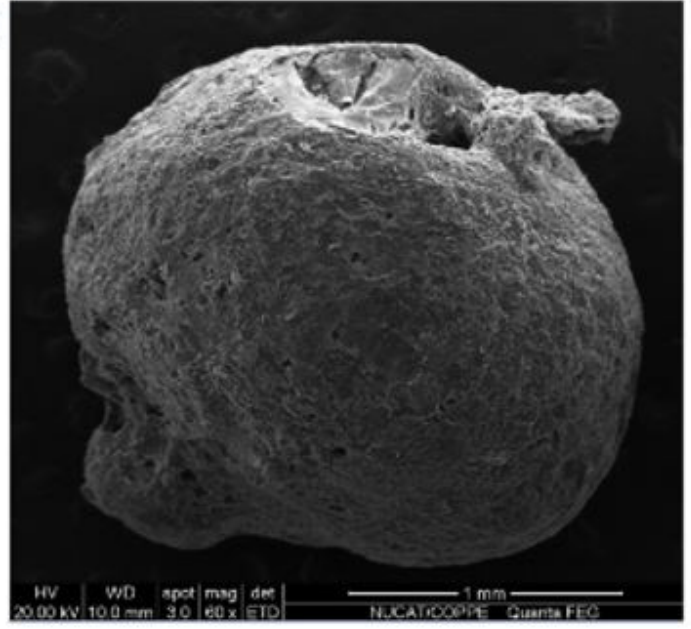

c)

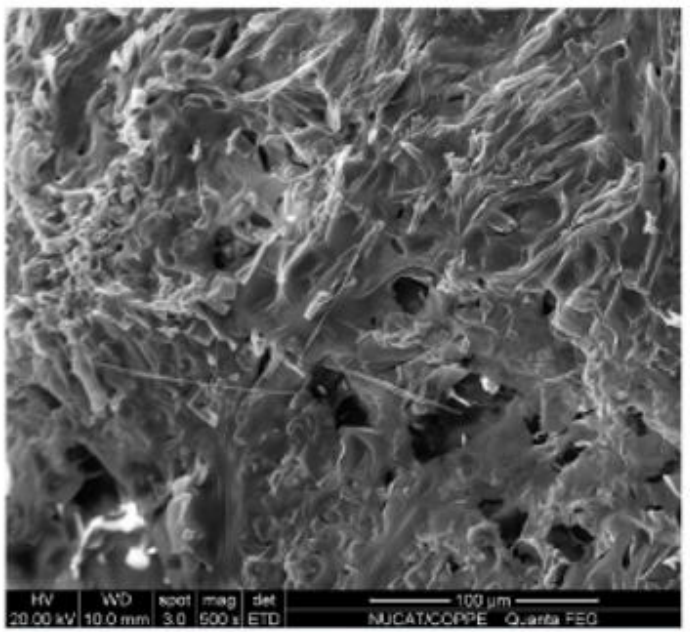

e)

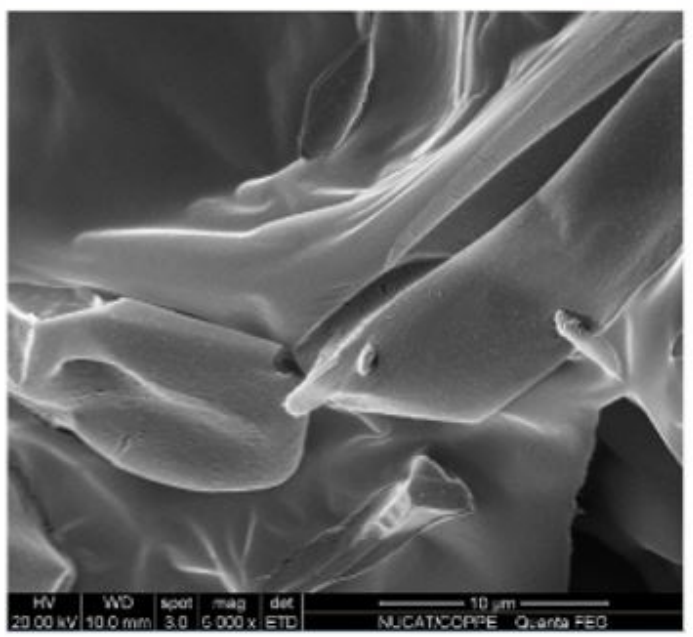

spherical and regular geometry (although slightly rough). This indicated that interruption of the flow rate allowed for higher conversion of the monomers into the copolymer, as also observed by FTIR analyses. b)

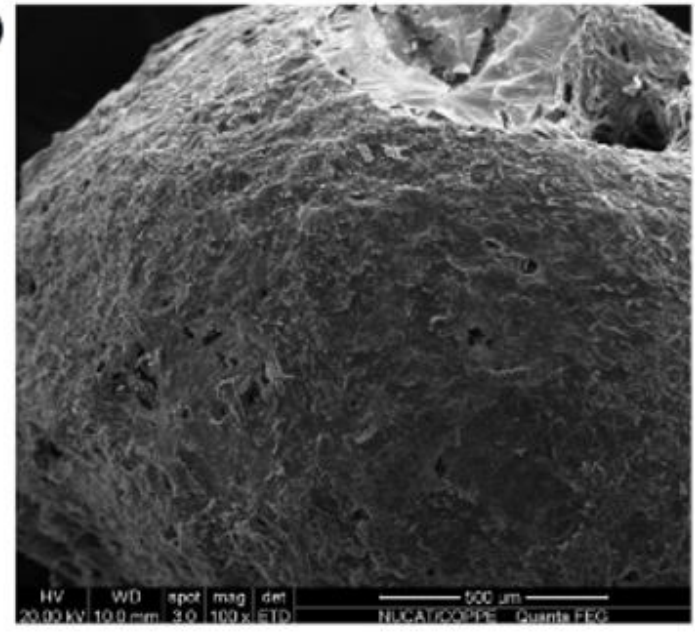

d)

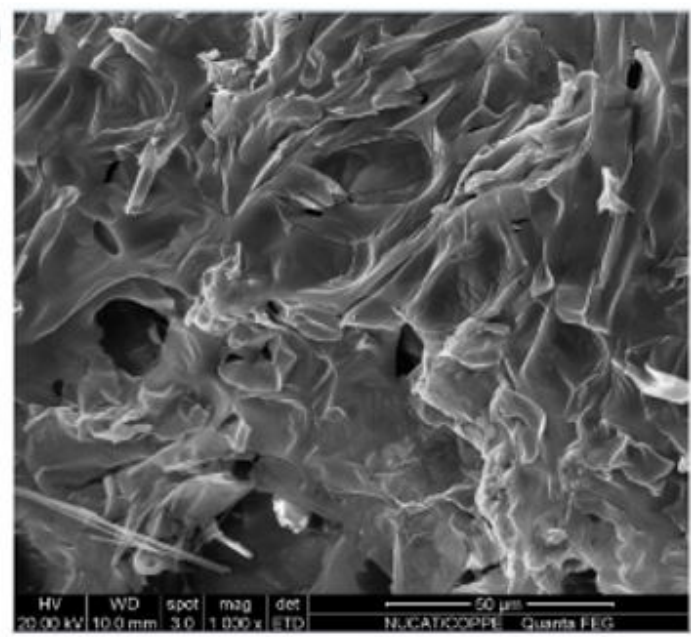

f)

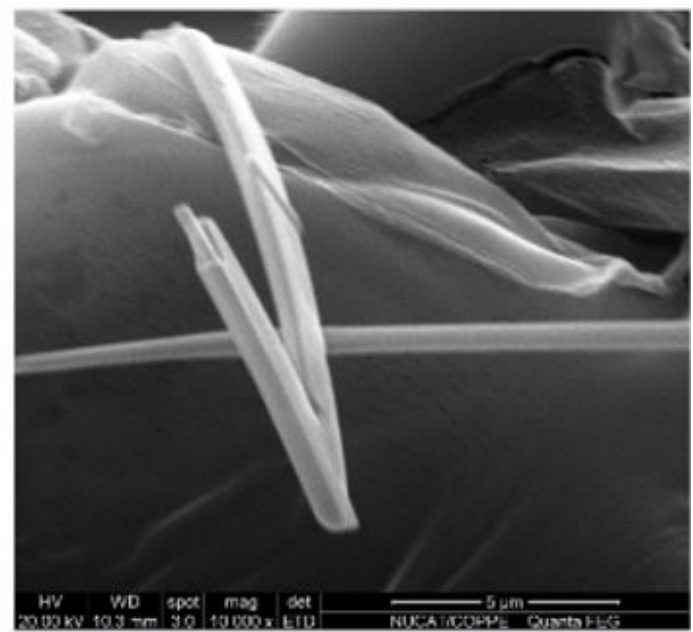

Figure 6. Images of coating 4 (polymeric solution; with pauses) obtained by SEM at magnifications of (a) $50 \times$; (b) $100 \times$; (c) $500 \times$; (d) $1,000 \times$; (e) $5,000 \times$; and (f) $10,000 \times$. 


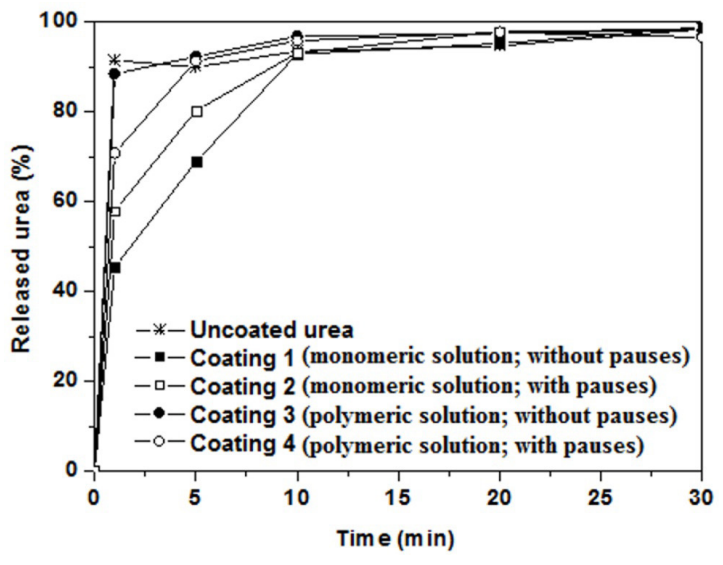

Figure 7. Release profiles of coatings 1, 2, 3, 4 and uncoated urea granules.

\subsection{Urea release profile in distilled water}

Figure 7 shows results of urea release tests in distilled water. It can be observed that the rate of dissolution of coated products was slower than observed for uncoated urea granules, indicating the existence of a polymer coating layer on urea granules after processing in the fluidized bed reactor.

Coatings 1 and 2, which used monomer solutions, apparently allowed for more efficient coating than Coatings 3 and 4, which were performed with the polymer solution, as also revealed by the slower urea release curves. This result is in accordance with the FTIR analyses, which revealed the formation of bonds between urea and the coating material, and the SEM analyses, which showed more regular coating in the first two cases.

It is important to note that these urea release tests were led out in an environment of extreme concentration, in pure water. In addition, the results obtained in this work seem promising for some agricultural applications, such as the prevention of ammonia evaporation.

\section{Conclusions}

Coated urea granules were produced in a fluidized bed reactor through in-situ copolymerization of acrylic acid and glycerol and addition of acrylic acid / glycerol copolymers in water. Coated and uncoated urea granules were characterized by Fourier transform infrared spectroscopy, scanning electron microscopy and rates of urea release in water. The obtained results indicated that it is possible to coat urea granules with polymer materials using the two proposed solutions. In particular, FTIR analyses indicated the formation of polymer layers and chemical interaction between urea and the polymer material. Besides, coating of the urea granules significantly reduced the number of pores on the surface and allowed for production of more regular and smoother surfaces, particularly when the in-situ polymerization scheme was applied. The rates of urea release in water showed that the coated granules exhibited slightly slower rates of dissolution due to the presence of the coating layer and reduced porosity of the granule surfaces.
Therefore, it was shown that it is possible to produce coated urea granules through in-situ polymerization onto the granule surface using a fluidized bed.

\section{Acknowledgements}

The authors thank CAPES (Coordenação de Aperfeiçoamento de Pessoal de Nível Superior), CNPq (Conselho Nacional de Pesquisa e Desenvolvimento Tecnológico) and FAPERJ (Fundação Carlos Chagas Filho de Apoio à Pesquisa do Estado do Rio de Janeiro) for their financial support and scholarships. The authors also thank Núcleo de Catálise (NUCAT) of COPPE/UFRJ for the SEM analyses.

\section{References}

1. Gowariker, V., Krishnamurthy, V. N., Gowariker, S., Dhanorkar, M., \& Paranjape, K. (2009). The fertilizer encyclopedia. New Jersey: John \& Wiley Sons.

2. Khan, S., \& Hanjra, M. A. (2009). Footprints of water and energy inputs in food production: Global perspectives. Food Policy, 34(2), 130-140. http://dx.doi.org/10.1016/j.foodpol.2008.09.001.

3. Zhao, G. Z., Liu, Y. Q., Tian, Y., Sun, Y. Y., \& Cao, Y. (2010). Preparation and properties of macromelecular slow-release fertilizer containing nitrogen, phosphorus and potassium. Journal of Polymer Research, 17(1), 119-125. http://dx.doi. org/10.1007/s10965-009-9297-4.

4. Newbould, P. (1989). The use of nitrogen fertiliser in agriculture: where do we go practically and ecolotically? Plant and Soil, 115(2), 297-311. http://dx.doi.org/10.1007/BF02202596.

5. Shaviv, A. (2001). Advances in controlled-release fertilizers. Advances in Agronomy, 71, 1-49. http://dx.doi.org/10.1016/ S0065-2113(01)71011-5.

6. Islam, M. R., Mao, S., Xue, X., Eneji, A. E., Zhao, X., \& Hu, Y. (2011). A lysimeter study of nitrate leaching, optimum fertilisation rate and growth responses of corn (Zea mays L.) following soil amendment with water-saving super-absorbent polymer. Journal of the Science of Food and Agriculture, 91(11), 1990-1997. http://dx.doi.org/10.1002/jsfa.4407. PMid:21480276.

7. Dave, A. M., Mehta, M. H., Aminabhavi, T. M., Kulkarni, A. R., \& Soppimath, K. S. (1999). A review on controlled release of nitrogen fertilizers through polymeric membrane devices. Polymer-Plastics Technology and Engineering, 38(4), 675-711. http://dx.doi.org/10.1080/03602559909351607.

8. Guo, M., Liu, M., Liang, R., \& Niu, A. (2006). Granular ureaformaldehyde slow-release fertilizer with superabsorbent and moisture preservation. Journal of Applied Polymer Science, 99(6), 3230-3235. http://dx.doi.org/10.1002/app.22892.

9. Tao, S., Liu, J., Jin, K., Qiu, X., Zhang, Y., Ren, X., \& Hu, S. (2011). Preparation and characterization of triple polymercoated controlled-release urea with water-retention property and enhanced durability. Journal of Applied Polymer Science, 120(4), 2103-2111. http://dx.doi.org/10.1002/app.33366.

10. Suherman, S., \& Anggoro, D. D. (2011). Producing slow release urea by coating with starch/aciylic acid influid bed spraying. IACSIT International Journal of Engineering and Technology, 11(6), 77-80. Retrieved in 2017, July 27, from http://citeseerx. ist.psu.edu/viewdoc/versions?doi=10.1.1.419.4865

11. Phillips, J. C. (2011). US Patent No 7,862,642. Washington: U.S. Patent and Trademark Office.

12. Liang, R., \& Liu, M. (2007). Preparation of poly (acrylic acid-co-acrylamide)/kaolin and release kinetics of urea from 
it. Journal of Applied Polymer Science, 106(5), 3007-3015. http://dx.doi.org/10.1002/app.26919.

13. Alizadeh, T. (2010). Preparation of molecularly imprinted polymer containing selective cavities for urea molecule and its application for urea extraction. Analytica Chimica Acta, 669(1-2), 94-101. http://dx.doi.org/10.1016/j.aca.2010.04.044. PMid:20510909.

14. Zhao, Y., Tan, T., \& Kinoshita, T. (2010). Swelling kinetics of poly (aspartic acid)/poly (acrylic acid) semi-interpenetrating polymer network hydrogels in urea solutions. Journal of Polymer Science. Part B, Polymer Physics, 48(6), 666-671. http://dx.doi.org/10.1002/polb.21936.

15. Mulder, W. J., Gosselink, R. J. A., Vingerhoeds, M. H., Harmsen, P. F. H., \& Eastham, D. (2011). Lignin based controlled release coatings. Industrial Crops and Products, 34(1), 915-920. http:// dx.doi.org/10.1016/j.indcrop.2011.02.011.

16. Crisp, S., Kent, B. E., Lewis, B. G., Ferner, A. J., \& Wilson, A. D. (1980). Glass-ionomer cement formulations. II. The synthesis of novel polycarboxylic acids. Journal of Dental Research, 59(6), 1055-1063. http://dx.doi.org/10.1177/0022 0345800590060801. PMid:6929290.

17. Villanova, J. C., Oréfice, R. L., \& Cunha, A. S. (2010). Aplicações farmacêuticas de polímeros. Polímeros: Ciência e Tecnologia, 20(1), 51-64. http://dx.doi.org/10.1590/S010414282010005000009 .

18. Pinto, M. C., Gomes, F. W., Melo, C. K., Melo, P. A., Jr., Castro, M., \& Pinto, J. C. (2012). Production of poly (acrylic acid) particles dispersed in organic media. Macromolecular Symposia, 319(1), 15-22. http://dx.doi.org/10.1002/masy.201100251.

19. Kaczmarek, H., \& Szalla, A. (2006). Photochemical transformation in poly (acrylic acid)/poly (ethylene oxide) complexes. Journal of Photochemistry and Photobiology A Chemistry, 180(1), 46-53. http://dx.doi.org/10.1016/j.jphotochem.2005.09.014.

20. Jin, S., Yue, G., Feng, L., Han, Y., Yu, X., \& Zhang, Z. (2011). Preparation and properties of a coated slow-release and waterretention biuret phosphoramide fertilizer with superabsorbent. Journal of Agricultural and Food Chemistry, 59(1), 322-327. http://dx.doi.org/10.1021/jf1032137. PMid:21155599.

21. Wang, Y., Liu, M., Ni, B., \& Xie, L. (2012). к-Carrageenansodium alginate beads and superabsorbent coated nitrogen fertilizer with slow-release, water-retention, and anticompaction properties. Industrial \& Engineering Chemistry Research, 51(3), 1413-1422. http://dx.doi.org/10.1021/ie2020526.

22. Liang, R., \& Liu, M. (2006). Preparation and properties of a double-coated slow-release and water-retention urea fertilizer. Journal of Agricultural and Food Chemistry, 54(4), 1392-1398. http://dx.doi.org/10.1021/jf052582f. PMid:16478265.

23. Lages, F., Silva-Graça, M., \& Lucas, C. (1999). Active glycerol uptake is a mechanism underlying halotolerance in yeasts: a study of 42 species. Microbiology, 145(9), 2577-2585. http:// dx.doi.org/10.1099/00221287-145-9-2577. PMid:10517611.
24. Arruda, P. V. D., Rodrigues, R. C. L. B., \& Felipe, M. D. A. (2007). Glicerol: um subproduto com grande capacidade industrial e metabólica. Reviews in Analgesia, 26, 56-62. Retrieved in 2017, July 27, from http://www.revistaanalytica. com.br/ed_anteriores/26/art04.pdf

25. Wang, S. (1974). US Patent No 3,842,022. Washington: U.S. Patent and Trademark Office.

26. Eritsyan, M. L., Gyurdzhyan, L. A., Melkonyan, L. T., \& Akopyan, G. V. (2006). Copolymers of acrylic acid with urea. Russian Journal of Applied Chemistry, 79(10), 1666-1668. http://dx.doi.org/10.1134/S1070427206100223.

27. Spychaj, T. (1989). Low molecular weight polymers of acrylic acid and copolymers with styrene. Progress in Organic Coatings, 17(2), 71-88. http://dx.doi.org/10.1016/0033-0655(89)80015-9.

28. Fernandes, B. S., Carlos Pinto, J., Cabral-Albuquerque, E., \& Fialho, R. L. (2015). Free-radical polymerization of urea, acrylic acid, and glycerol in aqueous solutions. Polymer Engineering and Science, 55(6), 1219-1229. http://dx.doi. org/10.1002/pen.24081.

29. Parikh, D., Bronck, J., \& Mogavero, M. (1996). Handbook of pharmaceutical granulation technology. New York: Marcel Dekker.

30. Kage, H., Dohzaki, M., Ogura, H., \& Matsuno, Y. (1999). Powder coating efficiency of small particles and their agglomeration in circulating fluidized bed. Korean Journal of Chemical Engineering, 16(5), 630-634. http://dx.doi.org/10.1007/ BF02708143.

31. Lan, R., Liu, Y., Wang, G., Wang, T., Kan, C., \& Jin, Y. (2011). Experimental modeling of polymer latex spray coating for producing controlled-release urea. Particuology, 9(5), 510516. http://dx.doi.org/10.1016/j.partic.2011.01.004.

32. Madhurambal, G., Mariappan, M., \& Mojumdar, S. C. (2010). TG-DTA, UV and FTIR spectroscopic studies of urea-thiourea mixed crystal. Journal of Thermal Analysis and Calorimetry, 100(3), 853-856. http://dx.doi.org/10.1007/s10973-010-0763-3.

33. Fischer, P. H. H., \& McDowell, C. A. (1960). The infrared absorption spectra of urea-hydrocarbon adducts. Canadian Journal of Chemistry, 38(2), 187-193. http://dx.doi.org/10.1139/ v60-025.

34. Krimm, S. (1955). Frequency shift of the CO stretching band in polypeptides and proteins. The Journal of Chemical Physics, 23(7), 1371-1372. http://dx.doi.org/10.1063/1.1742308.

35. Costa, M. M., Cabral-Albuquerque, E. C., Alves, T. L., Pinto, J. C., \& Fialho, R. L. (2013). Use of polyhydroxybutyrate and ethyl cellulose for coating of urea granules. Journal of Agricultural and Food Chemistry, 61(42), 9984-9991. http:// dx.doi.org/10.1021/jf401185y. PMid:24059839.

Received: July 27, 2017

Revised: Feb. 20, 2018

Accepted: June 01, 2018 